(C) Cambridge University Press 2016. This is an Open Access article, distributed under the terms of the Creative Commons Attribution licence (http://creativecommons.org/licenses/by/4.0/), which permits unrestricted re-use, distribution, and reproduction in any medium, provided the original work is properly cited.

\title{
Energy and nutrient intakes of young children in the UK: findings from the Gemini twin cohort
}

\author{
H. Syrad ${ }^{1}$, C. H. Llewellyn ${ }^{*}$, C. H. M. van Jaarsveld ${ }^{2}$, L. Johnson ${ }^{3}$, S. A. Jebb ${ }^{4}$ and J. Wardle ${ }^{1}$ \\ ${ }^{1}$ Department of Epidemiology and Public Health, Health Behaviour Research Centre, University College London, Gower Street, \\ London WC1E 6BT, UK \\ ${ }^{2}$ Department for Health Evidence \& Department of Primary and Community Care, Radboud University Medical Center, \\ PO Box 9101, 6500 HB Nijmegen, The Netherlands \\ ${ }^{3}$ School for Policy Studies, Centre for Exercise, Nutrition and Health Sciences, University of Bristol, 8 Priory Rd, Bristol BS8 1TZ, UK \\ ${ }^{4}$ Nuffield Department of Primary Care Health Sciences, University of Oxford, Radcliffe Observatory Quarter, Woodstock Road, \\ Oxford OX2 6GG, UK
}

(Submitted 11 August 2015 - Final revision received 8 February 2016 - Accepted 17 February 2016)

\section{Abstract}

Data on the diets of young children in the UK are limited, despite growing evidence of the importance of early diet for long-term health. We used the largest contemporary dietary data set to describe the intake of 21 -month-old children in the UK. Parents of 2336 children aged 21 months from the UK Gemini twin cohort completed 3-d diet diaries in 2008/2009. Family background information was obtained from questionnaires completed 8 months after birth. Mean total daily intakes of energy, macronutrients (g and \%E) and micronutrients from food and beverages, including and excluding supplements, were derived. Comparisons with UK dietary reference values (DRV) were made using $t$ tests and general linear regression models, respectively. Daily energy intake $(\mathrm{kJ})$, protein $(\mathrm{g})$ and most micronutrients exceeded DRV, except for vitamin $\mathrm{D}$ and $\mathrm{Fe}$, where 96 or $84 \%$ and 70 or $6 \%$ of children did not achieve the reference nutrient intake or lower reference nutrient intake (LRNI), respectively, even with supplementation. These findings reflect similar observations in the smaller sample of children aged 18-36 months in the National Diet and Nutrition Survey. At a population level, young children in the UK are exceeding recommended daily intakes of energy and protein, potentially increasing their risk of obesity. The majority of children are not meeting the LRNI for vitamin D, largely reflecting inadequate use of the supplements recommended at this age. Parents may need more guidance on how to achieve healthy energy and nutrient intakes for young children.

Key words: Nutrition: Energy intakes: Children: Diets

In recent years, it has been increasingly acknowledged that diet in early life may have an enduring impact on health ${ }^{(1)}$. During the first 2 years of life, dietary preferences and habits are established ${ }^{(2)}$. Optimising dietary quality in early life requires good data on the nutritional composition of young children's diets (total energy intake, macronutrients and micronutrients) in order to develop effective interventions. However, there are a few detailed large-scale national studies of dietary intake in this age group in the UK.

In 1994, the Avon Longitudinal Study of Pregnancy and Childhood (ALSPAC) collected 3-d dietary data from 1026 children aged 18 months in England, and daily intakes of energy and protein were higher than the recommended levels for children aged 2 years ${ }^{(3)}$. However, given the profound changes in the food environment, and the recorded increases in obesity prevalence in young children since this time ${ }^{(4)}$, it is possible that dietary intakes have changed. Dietary data on individuals aged 18 months and older in Britain are routinely collected as part of the National Diet and Nutrition Survey (NDNS) using 4-d unweighed diaries. Although the total sample for NDNS is large, the wide age range (18 months to 94 years) means that the sample size for young children is limited, with data for only 386 children aged 18-36 months in the period $2008-2012^{(5)}$. A larger scale, one-off survey conducted in the UK in 2011 (Diet and Nutrition Survey of Infants and Young Children) collected data on food and nutrient intakes from 2683 children aged 4-18 months, but this age range included both exclusively milk-fed infants and young children on an established solid-food diet ${ }^{(6)}$. Beyond 18 months of age, most children will be consuming little or no breast or formula milk ${ }^{(7)}$, and

Abbreviations: \%E, percentage of daily energy intake; DRV, dietary reference value; LRNI, lower reference nutrient intakes; NDNS, National Diet and Nutrition Survey; RNI, reference nutrient intake; SACN, Scientific Advisory Committee on Nutrition; SES, socio-economic status.

* Corresponding author: C. H. Llewellyn, email c.llewellyn@ucl.ac.uk 
we currently have limited information on young children's dietary intake at this vulnerable time.

The present study aimed to provide a detailed description of the dietary intake of very young children, at a time when weaning is close to, or at, completion. It used data from the UK Gemini twin cohort - a sample of 2336 UK children aged 21 months collected in 2008/2009 using 3-d unweighed diet diaries. This is a twin cohort established for research purposes; however, in order to determine whether the diets of these participants are reflective of a representative sample of children in the UK of this age, we compared the data with the NDNS rolling programme (20082012) of 386 children aged 18-36 months. We also compared the reported intakes with UK public health nutrition recommendations for energy and nutrient intakes at 2 years of age.

\section{Methods}

\section{Participants/recruitment}

The Gemini study is a UK birth cohort of twins, designed to assess genetic and environmental influences on early childhood growth. Families with twins born in England and Wales between March and December 2007 ( $n$ 6754) were asked by the Office for National Statistics whether their contact details could be passed to the Gemini research team. In total, 3435 families agreed to participate, and $70 \%$ of these families completed baseline questionnaires ( $n$ 2402); they constitute the Gemini sample. Gemini twins are representative of UK twins when compared based on sex, gestational age and birth weight ${ }^{(8,9)}$. Parents provided informed consent for children's participation in the Gemini study, and ethics approval was obtained from the University College London Committee for the Ethics of Non-National Health Service Human Research.

The NDNS rolling programme is an annual survey to monitor diet and nutrient intakes of a representative sample of the British population aged 18 months and older ${ }^{(5)}$. Households are selected using randomly selected postcodes and contacted by an interviewer to arrange a face-to-face interview and place a food diary. The sample used for comparison with the Gemini cohort contained 386 children aged 18-36 months.

\section{Measures}

Demographics. In the Gemini cohort, parents reported the sex, gestational age, date of birth of the children and whether they were breast-fed at all during the first 3 months of age. Maternal ethnicity was reported by parents, and dichotomised into white $(95.1 \%)$ and non-white $(4.9 \%)$. Family socio-economic status (SES) was defined using the National Statistics Socio-economic Class (NS-SEC) index based on occupation ${ }^{(10)}$. Parental occupations were categorised into higher, intermediate and lower SES ${ }^{1}$. Mothers reported the date of diary completion, from which we calculated the child's exact age. Birth weight was

${ }^{1}$ Higher and lower managerial and professional occupations were classified as higher SES, intermediate occupations, small employers and own account workers were classified as intermediate SES, and lower supervisory and technical occupations, (semi)routine occupations, never worked and longterm unemployed were classified as lower SES. obtained from health records, and weight SDS was calculated, which references children's weights against the population mean (weight SDS $=0$ ) in $1990^{(11)}$, for the child's age at measurement, sex and gestational age.

Parents of children in the NDNS rolling programme took part in a detailed interview and reported background information on demographic characteristics (age, sex, occupation, ethnicity). The NS-SEC index was used to define household SES ${ }^{(9)}$.

Diet diaries. Diet diaries were sent to all Gemini families ( $n$ 2402) between November 2008 and August 2009. Detailed instructions and portion guides, adapted from the pre-school food atlas ${ }^{(12)}$, provided guidance on estimating and recording all food and drinks consumed over $3 \mathrm{~d}$ (any 2 weekdays and 1 weekend day). Diet diaries were completed by 1357 families (56.5\% of baseline sample). Only children with $3 \mathrm{~d}$ of complete diary entries ( $n 1168$ families; $n 2336$ children) were included in the analyses. Energy and nutrient composition of all foods, drinks and vitamin supplements consumed were calculated using Diet In Nutrients Out (DINO), a dietary assessment programme ${ }^{(13)}$ incorporating the UK Food Standards Agency's NDNS nutrient databank ${ }^{(14)}$.

Parents of children in the NDNS were asked to complete a food diary for their child over 4 consecutive days. Energy and nutrient intakes were also calculated using DINO. In the first 4 years of the rolling programme, 4156 respondents (34\% of the selected households) completed food diaries, 386 of whom were parents of children aged 18-36 months.

\section{Analysis}

Energy and nutrient intake. Daily energy intake was derived for each child, averaged over $3 \mathrm{~d}$. Daily intakes of macronutrients and the components (total fat, SFA, protein, carbohydrate, starch, fibre and sugars ${ }^{2}$ ) were summarised as total $\mathrm{g}$ per $\mathrm{d}$ and percentage of daily energy intake (\%E). Daily intakes of selected micronutrients ( $\mathrm{Na}$, vitamin $\mathrm{C}$, thiamin, riboflavin, niacin, folate, vitamin $\mathrm{B}_{12}, \mathrm{Ca}$, vitamin $\mathrm{D}$, vitamin $\mathrm{A}$ and $\mathrm{Fe}$ ) were summarised as $\mathrm{mg}$ or $\mu \mathrm{g}$ per $\mathrm{d}$, both including and excluding supplement intake. Descriptive analyses including the mean, standard deviation, minimum, maximum, and 25th and 75 th percentile scores were computed for all dietary intake variables.

Comparison with the National Diet and Nutrition Survey. Data files for the first 4 years (2008/2009-2011/2012) of the NDNS rolling programme were obtained from the UK Data Archives (http://discover.ukdataservice.ac.uk/catalogue? $\mathrm{sn}=6533$ ). Average daily intakes of energy, macronutrients and micronutrients were available for children aged 18-36 months ${ }^{(5)}$. The data were weighted to adjust for potential bias in the results, including non-response bias, as well as known socio-demographic differences between the sample selected and the UK population. Weighted mean scores and

\footnotetext{
${ }^{2}$ Data on sugar components (non-milk extrinsic sugars and intrinsic milk sugars) was not available as it was not requested at the time the Human Nutrition Research Unit (Cambridge) coded the dietary data.
} 
intakes as a percentage of dietary reference values (DRV) were computed and compared with those in Gemini using linear regression models to test for differences. Models were adjusted for age, sex, ethnicity and SES.

Comparison with UK reference values. Adequacy of energy and nutrient intake was assessed by comparing intakes with age-/sex-specific UK DRV. Multiple criteria were used. Average daily energy intake was calculated as a percentage of the 2011 Scientific Advisory Committee on Nutrition $(\mathrm{SACN})^{(15)}$ estimated average requirement for children of 2 years of age. Intakes of protein and micronutrients were calculated as a percentage of the Department of Health reference nutrient intake (RNI) for children aged $1-3$ years ${ }^{(16)}$. Carbohydrate and fibre intakes were compared with the $\mathrm{SACN}^{(17)}$ recommendations for children aged 2-5 years. DRV for fats are unavailable for children under 5 years of age, and therefore comparisons could not be made. $\mathrm{Na}$ intake was calculated as a percentage of the updated RNI for children of 2 years of age by $\mathrm{SACN}^{(18)}$. To identify the proportion of children with inadequate intakes of micronutrients, we used the RNI and lower reference nutrient intake (LRNI) - the level at which intake is inadequate for $97.5 \%$ of the population ${ }^{(16)}$. An upper safe limit for vitamin A retinol activity equivalent of $800 \mu \mathrm{g}$ has been identified by the European Food Safety Authority ${ }^{(19)}$ and the percentage of children exceeding this limit was calculated. No upper limits were available for other micronutrients ${ }^{(19)}$.

One-sample $t$ tests compared daily intakes of energy, protein and micronutrients with DRV, and paired sample $t$ tests compared vitamin $\mathrm{D}$ and Fe intakes with and without supplementation.

\section{Results}

\section{Sample characteristics}

Table 1 shows the characteristics of the Gemini sample ( $n$ 2336). Children were on average $20 \cdot 6$ months old (SD 1.1) at diet diary completion, with similar proportions of boys ( $49.5 \%)$ and girls $(50.5 \%)$. The majority of families were of white ethnicity $(95 \cdot 1 \%)$. There were more mothers with higher SES (46\%) than intermediate $(16 \cdot 1 \%)$ or lower SES $(37.9 \%)$. The majority of children $(62.8 \%)$ were breast-fed to some degree in the first 3 months of life. Compared with the Gemini sample, NDNS children ( $n$ 386) were slightly older (26.4 months) (Table 1), with a greater proportion of boys (53.6\%) than girls, more children of non-white ethnicity (15\%) and fewer mothers with higher SES (40.9\%).

\section{Dietary intake in the Gemini sample}

Table 2 shows the average daily energy and nutrient intakes from food, beverages and supplements for the Gemini sample. Daily energy intake was $4330 \mathrm{~kJ}: 12 \%$ energy from proteins, $51 \%$ energy from carbohydrates and $37 \%$ energy from fat. Children consumed $18 \%$ of energy from SFA, $27 \%$ of energy from sugars and $8 \mathrm{~g} / \mathrm{d}$ of fibre. Vitamin D intake was $2.3 \mu \mathrm{g} / \mathrm{d}$, and Fe intake was $6.4 \mathrm{mg} / \mathrm{d}$. In addition, $60 \mathrm{mg}$ of vitamin $\mathrm{C}$ and $842 \mathrm{mg}$ of Ca were consumed per d; $\mathrm{Na}$ intake was $1148 \mathrm{mg} / \mathrm{d}$.

\section{Comparisons with the National Diet and Nutrition Survey}

Table 2 compares the energy, macronutrient and micronutrient intakes of the Gemini sample with the NDNS. Daily energy intakes were lower in the Gemini cohort than in the NDNS $(P=0.001)$, but \%E from fat and SFA were higher in the Gemini cohort than in the NDNS by 3 percentage points each, $P<0 \cdot 01$. Protein $\% \mathrm{E}$ was lower than in the NDNS by 3 percentage points, $P<0 \cdot 001$. Vitamin D and Fe intakes in the Gemini cohort were almost identical to the NDNS sample.

\section{Comparisons with dietary reference values}

Table 3 compares the daily energy intake and nutrient intakes (including supplements) of the Gemini sample with UK DRV. Mean daily energy intake significantly exceeded the level recommended by the SACN for children aged 2 years $(P<0.001)$; $63 \%$ exceeded the recommendation. Protein intake was almost three times higher than that recommended $(P<0 \cdot 001)$, with only $0 \cdot 1 \%$ of children not meeting the RNI. Fibre intake was significantly lower than that recommended $(P<0 \cdot 001)$.

At a population level, RNI set by the Department of Health ${ }^{(16)}$ were met for all micronutrients except vitamin $\mathrm{D}$ and Fe. Vitamin D intake, including supplements, was less than half of that recommended $(P<0.001)$. Only $6.8 \%$ of the sample met the

Table 1. Sample characteristics in the Gemini twin study $(n 2336)$ and National Diet and Nutrition Survey (NDNS) ( $n$ 386) (Mean values and standard deviations; numbers and percentages)

\begin{tabular}{|c|c|c|c|c|}
\hline \multirow[b]{2}{*}{ Characteristics } & \multicolumn{2}{|c|}{ Gemini } & \multicolumn{2}{|c|}{ NDNS } \\
\hline & Mean & SD & Mean & SD \\
\hline Age at diet diary completion (months) & $20 \cdot 6$ & 1.1 & $26 \cdot 4$ & $8 \cdot 8$ \\
\hline Weight at birth $(\mathrm{kg})$ & 2.5 & 0.5 & - & \\
\hline Weight SDS at birth* & -0.5 & 0.9 & - & \\
\hline \multirow[t]{2}{*}{ Gestational age (weeks) } & $36 \cdot 2$ & $2 \cdot 5$ & - & \\
\hline & $n$ & $\%$ & $n$ & $\%$ \\
\hline \multicolumn{5}{|l|}{ Feeding method $0-3$ months $†$} \\
\hline Breast-fed infants (\%) & 1468 & 62.8 & - & \\
\hline Bottle-fed infants & 868 & 37.2 & - & \\
\hline \multicolumn{5}{|l|}{ Sex } \\
\hline Boys & 1157 & 49.5 & 207 & 53.6 \\
\hline Girls & 1179 & 50.5 & 179 & $46 \cdot 4$ \\
\hline \multicolumn{5}{|l|}{ Ethnicity } \\
\hline White & 2222 & $95 \cdot 1$ & 328 & $85 \cdot 0$ \\
\hline Non-white & 106 & 4.9 & 58 & $15 \cdot 0$ \\
\hline \multicolumn{5}{|l|}{ Socio-economic status $\ddagger$} \\
\hline High & 1056 & 46 & 158 & $40 \cdot 9$ \\
\hline Intermediate & 370 & $16 \cdot 1$ & 79 & 20.5 \\
\hline Low & 872 & 37.9 & 149 & 38.6 \\
\hline
\end{tabular}

* Weight SDS references children's weights against the population mean (weight SDS $=0$ ) in $1990^{(11)}$, for the child's age at measurement, sex and gestational age. A weight SDS $>0$ indicates higher weight, and a weight $S D S<0$ indicates lower weight compared with children of the same age, sex and gestational age.

t The proportion of infants breast-fed in the first 3 months from birth was obtained with the question 'which feeding method did you use in the first 3 months?' with response options ranging from $1=$ entirely breast-feeding to $6=$ entirely bottle feeding. Categories $1-5$ were classified as 'breast-fed' and category 6 as 'bottle-fed'.

$\ddagger$ Classified using the Office for National Statistics ${ }^{(10)}$ and grouped into higher (higher and lower managerial and professional occupations), intermediate (intermediate occupations, small employers and own account workers) and lower socioeconomic status (lower supervisory and technical occupations, (semi)routine occupations, never worked and long-term unemployed). 
Table 2. Mean intake of energy and nutrients from food, beverages and supplements of children in the Gemini twin sample ( $n$ 2336) and comparisons with the National Diet and Nutrition Survey (NDNS) ( $n$ 386) (Mean values with their standard errors)

\begin{tabular}{|c|c|c|c|c|c|}
\hline \multirow[b]{2}{*}{ Dietary Intake } & \multicolumn{2}{|c|}{ Gemini (21 months) } & \multicolumn{2}{|c|}{$\begin{array}{c}\text { NDNS } \dagger \\
\text { (18-36 months) }\end{array}$} & \multirow[b]{2}{*}{$P \neq$} \\
\hline & Mean & SE & Mean & $\mathrm{SE}$ & \\
\hline Daily energy intake (kJ) & $4330^{*}$ & 67 & $4728^{*}$ & 64 & $0.001^{x}$ \\
\hline Fat $(g / d)$ & 42 & 0.2 & 43 & 0.8 & 0.46 \\
\hline Fat (\%E) & $37^{\star}$ & 0.1 & $34^{*}$ & 0.3 & $0.001^{*}$ \\
\hline SFA (g/d) & 20 & 0.1 & 19 & 0.4 & 0.225 \\
\hline SFA (\%E) & $18^{*}$ & 0.1 & $15^{\star}$ & 0.2 & $<0.001^{*}$ \\
\hline Protein $(\mathrm{g} / \mathrm{d})$ & 40 & 0.2 & 43 & 0.6 & 0.07 \\
\hline Protein (\%E) & $12^{*}$ & 0.04 & $15^{\star}$ & 0.1 & $<0.001^{*}$ \\
\hline Carbohydrate $(\mathrm{g} / \mathrm{d})$ & $132^{*}$ & 0.6 & $152^{*}$ & $2 \cdot 1$ & $<0.001^{\star}$ \\
\hline Carbohydrate (\%E) & 51 & 0.1 & 51 & 0.3 & 0.05 \\
\hline Starch & $62^{*}$ & 0.4 & $77^{*}$ & $1 \cdot 2$ & $<0.001^{*}$ \\
\hline Starch (\%E) & 24 & 0.1 & 26 & 0.4 & 0.63 \\
\hline Total sugars $(g / d) \S$ & $69^{*}$ & 0.4 & $75^{\star}$ & $1 \cdot 6$ & $<0.001^{*}$ \\
\hline Total sugars $(\% \mathrm{E}) \S$ & 27 & 0.1 & 25 & 0.4 & 0.17 \\
\hline Dietary fibre as NSP $(\mathrm{g} / \mathrm{d})$ & 8 & 0.1 & 8 & 0.2 & 0.90 \\
\hline $\mathrm{Na}(\mathrm{mg} / \mathrm{d})$ & 1148 & $7 \cdot 0$ & 1318 & 24 & 0.51 \\
\hline Vitamin C $(\mathrm{mg} / \mathrm{d})$ & 60 & 0.6 & 73 & 3.3 & 0.01 \\
\hline Thiamin (mg/d) & 0.9 & 0.01 & 1.0 & 0.1 & 0.86 \\
\hline Riboflavin $(\mathrm{mg} / \mathrm{d})$ & 1.7 & 0.01 & 1.4 & 0.03 & 0.02 \\
\hline Niacin $(\mathrm{mg} / \mathrm{d})$ & $9 \cdot 8^{*}$ & 0.1 & $19 \cdot 5^{\star}$ & 0.3 & $<0.001^{*}$ \\
\hline Folate ( $\mu \mathrm{g} \mathrm{DFE/d)}$ & 159 & 0.9 & 150 & $2 \cdot 6$ & 0.13 \\
\hline Vitamin $B_{12}(\mu \mathrm{g} / \mathrm{d})$ & $4 \cdot 2$ & 0.03 & 3.9 & 0.1 & 0.77 \\
\hline $\mathrm{Ca}(\mathrm{mg} / \mathrm{d})$ & 842 & 4.8 & 774 & $15 \cdot 3$ & 0.29 \\
\hline Vitamin D $(\mu \mathrm{g} / \mathrm{d})$ & $2 \cdot 3$ & 0.1 & $2 \cdot 2$ & 0.1 & 0.51 \\
\hline Vitamin A ( $\mu \mathrm{g}$ RAE/d) & 551 & 5.9 & 568 & $18 \cdot 9$ & 0.64 \\
\hline $\mathrm{Fe}(\mathrm{mg} / \mathrm{d})$ & 6.4 & 0.1 & 6.4 & 0.1 & 0.82 \\
\hline
\end{tabular}

RNI (Table 3). Only $30 \%$ of children met the RNI for Fe with $6.3 \%$ below the LRNI. Na intake was more than double the RNI set by SACN in $2003^{(18)}$. Almost all children (98.8\% of the sample) exceeded the recommended level of intake. In many other cases, micronutrient intakes, including vitamin $\mathrm{C}$, riboflavin, folate, $\mathrm{Ca}$ and vitamin $\mathrm{B}_{12}$, far exceeded the recommended levels. Even without supplementation, all micronutrient intakes, except vitamin D and Fe, exceeded RNI (Table 4). Vitamin D intake increased with supplementation $(P<0 \cdot 001)$, as did Fe intake $(P<0 \cdot 001)$, but in the absence of supplementation only 10.9 and $84.5 \%$ of children exceeded the LRNI. Among those children taking supplements ( $n 173 ; 7 \cdot 4 \%$ ), the average intake of vitamin D was $6.8 \mu \mathrm{g} / \mathrm{d}$; however, $54.9 \%$ of children still did not meet the RNI and $31.8 \%$ the LRNI. Fe intake among those taking supplements was $8.5 \mu \mathrm{g} / \mathrm{d}$, yet the RNI was still not met by $60.7 \%$ and the LRNI by $2 \cdot 9 \%$.

\section{Discussion}

This study describes the dietary intake of 2336 British children aged 21 months. It extends an earlier analysis of the determinants of energy and macronutrient intakes ${ }^{(20)}$ by describing additional dietary components and makes comparisons with the smaller, but nationally representative, NDNS sample. This demonstrates that the assessment of dietary intake in the Gemini cohort is broadly representative and can provide valuable insights into the dietary intake of young children in the UK in a large sample of young children.

Energy intake was on average $7 \%$ higher than the values recommended for 2-year-old children in the UK, and although the mean difference was small $(280 \mathrm{~kJ} / \mathrm{d})$, if sustained it will lead to excessive weight gain over time. Children were only 21 months old, not 2 years ( 24 months) old, and thus should have lower energy needs. In conjunction with previous similar findings from the NDNS ${ }^{(21,22)}$, it is clear that excessive energy intakes in young children are a concern.

Protein intake was almost three times higher than that recommended for children aged $1-3$ years - a matter of concern in the light of evidence of a positive association between protein intake and adiposity in children ${ }^{(23,24)}$. We have previously shown in the Gemini cohort that protein intake at 21 months of age is positively related to increases in BMI and weight up to 5 years $^{(25)}$. This is supported by a longitudinal 
Table 3. Mean intake of energy, macronutrients and micronutrients from food, beverages and supplements of children in the Gemini twin sample ( $n$ 2336) aged 21 months and comparisons with dietary reference values (DRV)

(Mean values, percentages, standard errors, and 25th and 75th percentiles)

\begin{tabular}{|c|c|c|c|c|c|c|c|c|c|c|c|}
\hline Nutrients & DRV & LRNI & Meant & $\%$ of DRV & $\begin{array}{c}\% \text { of sample } \\
\text { not meeting DRV }\end{array}$ & $\begin{array}{c}\% \text { of sample } \\
\text { not meeting LRNI }\end{array}$ & SE & 25th percentile & 75th percentile & Minimum-maximum & $P \ddagger$ \\
\hline Daily energy intake (kJ) & $4050^{\star} \S$ & - & $4330^{*}$ & $107 \S$ & 37 & - & 67 & 3794 & 4786 & 1770-8569 & $<0.001^{*}$ \\
\hline Total fat $(\mathrm{g} / \mathrm{d})$ & - & - & \multicolumn{2}{|c|}{42} & - & - & 0.2 & 35 & 49 & 13-86 & - \\
\hline Total fat (\%E) & - & - & \multicolumn{2}{|c|}{37} & - & - & 0.1 & 34 & 40 & $18-57$ & - \\
\hline SFA $(g / d)$ & - & - & \multicolumn{2}{|c|}{20} & - & - & 0.1 & 16 & 24 & $3-42$ & - \\
\hline SFA (\%E) & - & - & \multicolumn{2}{|c|}{18} & - & - & 0.1 & 15 & 20 & $4-33$ & - \\
\hline Protein $(\mathrm{g} / \mathrm{d})$ & $14 \cdot 5^{\star} \|$ & - & $40^{*}$ & 276 & 0.1 & - & 0.2 & 34 & 45 & $11-76$ & $<0.001^{*}$ \\
\hline Protein $(\% \mathrm{E})$ & - & - & \multicolumn{2}{|c|}{12} & - & - & 0.04 & 11 & 14 & $7-20$ & - \\
\hline Total carbohydrates $(\mathrm{g} / \mathrm{d})$ & - & - & \multicolumn{2}{|c|}{132} & - & - & 0.6 & 114 & 148 & $52-269$ & - \\
\hline Total carbohydrates (\%E) & $50 * \pi$ & - & $51^{\star}$ & 102 & - & - & 0.1 & 47 & 55 & $26-77$ & $<0.001^{*}$ \\
\hline Starch & - & - & \multicolumn{2}{|c|}{62} & - & - & 0.4 & 50 & 72 & $13-167$ & - \\
\hline Starch (\%E) & - & - & \multicolumn{2}{|c|}{24} & - & - & 0.1 & 21 & 27 & $6-58$ & - \\
\hline Total sugars $(\mathrm{g} / \mathrm{d})$ & - & - & \multicolumn{2}{|c|}{69} & - & - & 0.4 & 57 & 80 & $21-165$ & - \\
\hline Total sugars (\%E) & - & - & \multicolumn{2}{|c|}{27} & - & - & 0.1 & 24 & 30 & $8-49$ & - \\
\hline Dietary fibre as NSP (g/d) & $15^{\star} \mathbb{I}$ & - & $8^{*}$ & 53 & - & - & 0.12 & 6 & 9 & $1-20$ & $<0.001^{*}$ \\
\hline $\mathrm{Na}(\mathrm{mg} / \mathrm{d})$ & $500^{*}+\dagger$ & 200 & $1148^{*}$ & 230 & $1 \cdot 2$ & 0 & $7 \cdot 0$ & 914 & 1350 & $221-2727$ & $<0.001^{*}$ \\
\hline Vitamin C (mg/d) & $30 * \|$ & 8 & $60^{*}$ & 200 & 13.5 & 0 & 0.6 & 38 & 77 & $11-226$ & $<0.001^{*}$ \\
\hline Thiamin $(\mathrm{mg} / \mathrm{d})$ & $0.5^{\star} \|$ & 0.23 & $0.9^{*}$ & 180 & 1.7 & 0 & 0.01 & 0.7 & 1.0 & $0.4-5.8$ & $<0.001^{*}$ \\
\hline Riboflavin (mg/d) & $0.6^{*} \|$ & 0.3 & $1 \cdot 7^{\star}$ & 283 & $1 \cdot 1$ & 0 & 0.01 & 1.3 & $2 \cdot 0$ & $0 \cdot 3-6 \cdot 0$ & $<0.001^{*}$ \\
\hline Niacin (mg/d) & $8^{*} \|$ & 4.4 & $9 \cdot 8^{\star}$ & 123 & $32 \cdot 1$ & 1 & 0.1 & 7.5 & 11.3 & $2 \cdot 4-61 \cdot 3$ & $<0.001^{*}$ \\
\hline Folate ( $\mu \mathrm{g}$ DFE/d) & $70 * \|$ & 35 & $160^{\star}$ & 227 & 0.3 & 0 & 0.9 & 130 & 184 & $46 \cdot 7-429$ & $<0.001^{*}$ \\
\hline Vitamin $B_{12}(\mu \mathrm{g} / \mathrm{d})$ & $0.5^{\star} \|$ & 0.3 & $4 \cdot 2^{*}$ & 840 & 0.2 & 0 & 0.03 & $3 \cdot 1$ & $5 \cdot 2$ & $0.3-13.4$ & $<0.001^{*}$ \\
\hline $\mathrm{Ca}(\mathrm{mg} / \mathrm{d})$ & $350 * \|$ & 200 & $842^{*}$ & 241 & 1.3 & 0.1 & 4.8 & 686 & 973 & $187-1905$ & $<0.001^{*}$ \\
\hline Vitamin D $(\mu \mathrm{g} / \mathrm{d})$ & $7^{*} \|$ & $3.9 \neq \ddagger$ & $2 \cdot 3^{*}$ & 33 & 93.2 & 84.2 & 0.1 & 0.9 & 2.5 & $0-16 \cdot 3$ & $<0.001^{*}$ \\
\hline Vitamin A ( $\mu \mathrm{g}$ RAE/d) & $400 * \|$ & 200 & $551^{*}$ & 138 & $27 \cdot 6$ & 1.6 & 5.9 & 389 & 639 & $72-4265$ & $<0.001^{*}$ \\
\hline $\mathrm{Fe}(\mathrm{mg} / \mathrm{d})$ & $6 \cdot 9^{*} \|$ & 3.7 & $6 \cdot 4^{\star}$ & 93 & 69.8 & $6 \cdot 3$ & 0.1 & 4.8 & $7 \cdot 3$ & $1 \cdot 1-96 \cdot 1$ & $<0.001^{*}$ \\
\hline
\end{tabular}

LRNI, lower reference nutrient intakes; \%E, percentage of daily energy intake; RAE, retinol activity equivalent; DFE, dietary folate equivalent.

* Significant differences.

I $P$-value for difference between mean intake of children in the Gemini sample and the DRV.

$\S$ DRV for daily energy intake is based on the Scientific Advisory Committee on Nutrition (SACN) ${ }^{(15)}$ estimated average requirements (EAR) for children of 2 years of age and the mid-point of DRV for males (4201 kJ/d or $\left.1004 \mathrm{kcal} / \mathrm{d}\right)$ and females $(3899 \mathrm{~kJ} / \mathrm{d}$ or $932 \mathrm{kcal} / \mathrm{d})$.

II RNI for children of 1-3 years of age from the Department of Health ${ }^{(16)}$

T RNI for children of 2-5 years of age from SACN ${ }^{(17)}$.

t† RNI for children of $1-3$ years of age from SACN ${ }^{(18)}$

㧊 Calculated as $75 \%$ of EAR $(5 \cdot 25 \mu \mathrm{g} / \mathrm{d})$. 


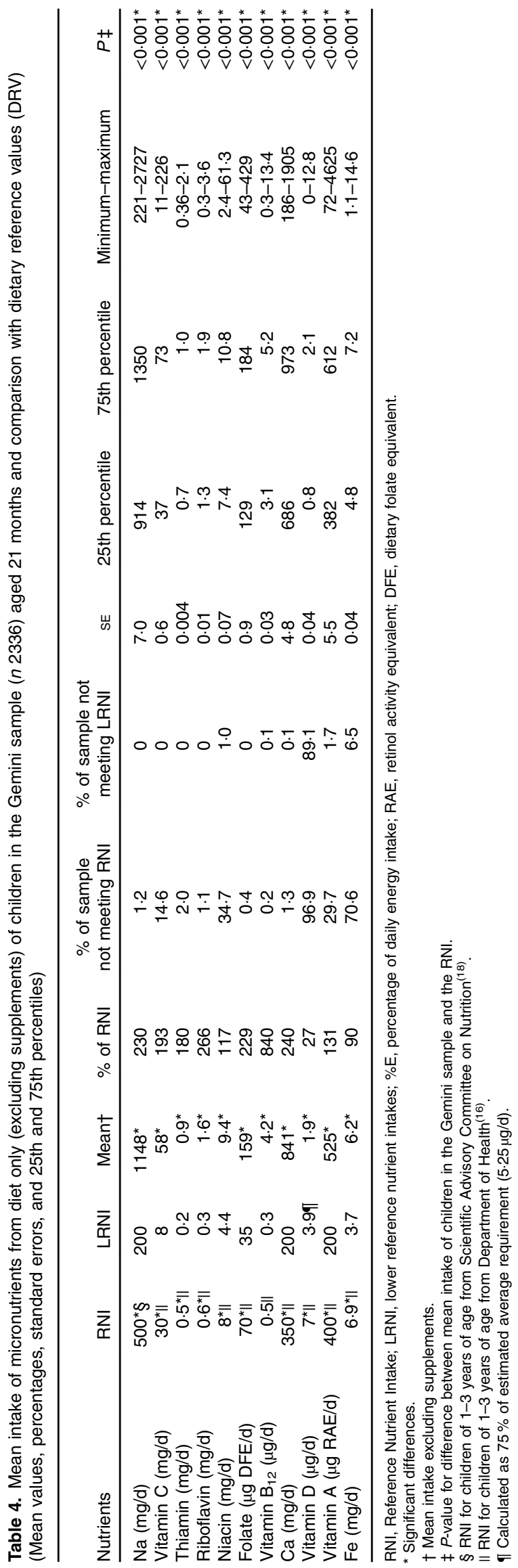

study by Günther et al. ${ }^{(26)}$, which demonstrated that a high protein intake during the complementary feeding period (12-24 months) was associated with higher BMI SDS and percentage body fat at 7 years of age. The high protein intake of young children in the UK could potentially be placing them at risk for overweight later in life.

Intake of many micronutrients was higher than that recommended. More attention needs to be given to the risks of high intakes and should be monitored as part of population risk assessments. The high intake of $\mathrm{Na}$ echoes findings from the NDNS and is an ongoing cause for concern. High intakes of $\mathrm{Na}$ are associated with elevated blood pressure and adverse cardiovascular health in adults ${ }^{(27)}$. Moreover, Na intake reported in this study is likely to be underestimated, as salt added during cooking and at the table is poorly reported $^{(28)}$.

A large proportion of children failed to meet the LRNI for vitamin $\mathrm{D}$ and $\mathrm{Fe}$, and inadequate intake of these nutrients has been associated with poor health ${ }^{(29,30)}$. Supplements increased intakes in the $7 \%$ of children that used them, but the majority of children (84.2\%) were still not meeting the LRNI for vitamin D, underlining the importance of the current government recommendations that all children aged 6 months to 5 years should take a daily supplement containing vitamin $\mathrm{D}^{(31)}$. A recent draft report by $\mathrm{SACN}^{(32)}$ recommends increasing the intake of vitamin D from $7-10 \mu \mathrm{g} / \mathrm{d}$ for children aged $1-4$ years, which would mean $96.9 \%$ of children fall below the recommended intake. A smaller proportion (6.3\%) did not meet the LRNI for Fe and $70 \%$ did not meet the RNI, even with supplements. Vitamin D and Fe intakes also fell short of recommendations in the NDNS sample ${ }^{(21,22)}$. Many toddler milks and foods are now fortified with Fe but there is also a need to provide more guidance to parents on identifying other, regular foods that are good sources of Fe.

There have been relatively few changes in nutrient intakes in young children from those reported in the 1994 ALSPAC study. Average energy intakes were slightly higher than those reported in the present study ( $4530 \mathrm{~kJ}$ in ALSPAC $v .4330 \mathrm{~kJ}$ in Gemini). However, the differences between the two studies are quantitatively small and may be an artefact due to differences in the participants or in the dietary assessment methodology, or there may be a contemporary trend towards under-reporting. This has been previously reported in adults ${ }^{(33)}$, and as food diaries were completed by parents, this trait may extend to the reporting of children's intake. Intakes of vitamin D and Fe have apparently increased, perhaps suggesting an increase in the uptake of supplements, and/or the use of fortified milks and foods since 1994. Indeed, it was not until 1997 that the use of fortified formula milks became widespread ${ }^{(34)}$. Nonetheless, it is difficult to draw robust conclusions about secular trends based on these two rather different studies.

\section{Strengths and limitations}

We have described the dietary intakes of young children aged 21 months using the largest dietary data set for children of this age in the UK, and we have also shown that these data are broadly representative of the UK at large with reference to the 
nationally representative NDNS. This suggests that the Gemini cohort represents a valuable resource for studies of diet and health outcomes as the prospective design enables causal associations to be investigated.

However, methodological differences between the two samples must be acknowledged. The Gemini sample includes more children of white ethnicity and higher SES than the NDNS sample, and is a cohort of families who have chosen to participate, rather than being invited, which might account for some of the differences observed between the two samples, such as lower $\mathrm{Na}$ intake in the Gemini cohort, indicating potentially healthier diets. Children in the NDNS were also slightly older and their diets contained less milk and more of other foods. The Gemini dietary data were collected using 3-d diaries rather than 4-d diaries used in the NDNS, which may have resulted in more variation in intake in the Gemini sample, although both purport to reflect habitual intake. More importantly, the short recording period in both studies may not adequately reflect habitual diet ${ }^{(35)}$, especially for micronutrients that are ingested along with foods consumed sporadically, and in young children whose eating habits may be erratic. Nutrient and energy intakes of both samples were computed using the same dietary assessment programme (DINO), and thus analytical differences were minimised. Unweighed diet diaries are considered a reliable method to estimate energy intake in children ${ }^{(36)}$, and have been validated for energy against the doubly labelled water method ${ }^{(37)}$. Portion guides helped to ensure standardisation of reporting.

\section{Conclusion}

Young children in the UK have intakes of energy and protein that are higher than recommended levels and potentially increase the risk of obesity. High intakes of $\mathrm{Na}$ are also a concern as they may set taste preference for the future and increase the risk of elevated blood pressure. Many young children are not consuming sufficient vitamin D and Fe. Greater guidance and support for parents on the appropriate type, amount and variety of foods and beverages, together with appropriate micronutrient supplementation, are required.

\section{Acknowledgements}

The authors thank all the Gemini families who completed the diet diaries and the MRC Human Nutrition Research Unit, Cambridge, for coding the diaries.

The NDNS is funded by the Department of Health, UK, and data were made available to researchers under license via the UK Data Archive. All phases of this study were supported by Cancer Research UK (grant number 161722) and the Medical Research Council (grant number 160897). Nutricia Ltd (grant number 157582) provided a contribution to the funding for the coding and analysis of the dietary data but had no role in the design, analysis or writing of this article.

H. S. contributed to the conception and design of the study, data collection, analysis, interpretation of findings and wrote the first draft of the manuscript; C. H. L. contributed to the conception and design of the study, the interpretation of the findings, reviewed and revised the manuscript and approved the final manuscript as submitted; C. H. M. v. J. contributed to the interpretation of the findings, reviewed and revised the manuscript and approved the final manuscript as submitted; L. J. designed the Gemini diet diaries, coordinated the dietary data collection, contributed to the interpretation of the findings, reviewed and revised the manuscript and approved the final manuscript as submitted; S. A. J. contributed to the interpretation of the findings, reviewed and revised the manuscript and approved the final manuscript as submitted; J. W. contributed to the conception and design of the study, the interpretation of the findings, and reviewed and revised the manuscript and approved the final manuscript as submitted.

The authors declare that there are no conflicts of interest.

\section{References}

1. Summerbell CD, Douthwaite W, Whittaker V, et al. (2009) The association between diet and physical activity and subsequent excess weight gain and obesity assessed at 5 years of age or older: a systematic review of the epidemiological evidence. Int J Obes (Lond) 33, Suppl. 3, S1-92.

2. Birch L, Savage JS, Ventura A, et al. (2007) Influences on the development of children's eating behaviours: from infancy to adolescence. Can J Diet Pract Res 68, s1-s56.

3. Cowin I \& Emmett P (2007) Diet in a group of 18-month-old children in South West England, and comparison with the results of a national survey. J Hum Nutr Diet 20, $254-267$.

4. Stamatakis E, Zaninotto P, Falaschetti E, et al. (2010) Time trends in childhood and adolescent obesity in England from 1995 to 2007 and projections of prevalence to 2015. J Epidemiol Community Health 64, 167-174.

5. Bates B, Lennox A, Prentice A, et al. (2014) National Diet and Nutrition Survey: Results from Years 1-4 (combined) of the Rolling Programme (2008/2009-2011/12). Department of Health and Food Standards Agency. https://www.gov. uk/government/uploads/system/uploads/attachment_data/file/ 310995/NDNS_Y1_to_4_UK_report.pdf (accessed August 2015).

6. Lennox A, Sommerville J, Ong K, et al. (2013) Diet and Nutrition Survey of Infants and Young Children, 2011. Department of Health and Food Standards Agency. https:// www.gov.uk/government/uploads/system/uploads/attachment_ data/file/139572/DNSIYC_UK_report_ALL_chapters_DH_V10.0. pdf (accessed August 2015).

7. Stephen AM, Sommerville JP, Henderson H, et al. (2013) Food consumption in the Diet and Nutrition Survey of Infants and Young Children 2011 (DNSIYC). Proc Nutr Soc 72, E121.

8. Office for National Statistics (2007) Birth Statistics Series FM1 no. 35. Review of the Registrar General on Births and Patterns of Family Building in England and Wales, 2006. Newport: Office for National Statistics.

9. Van Jaarsveld CH, Johnson L, Llewellyn C, et al. (2010) Gemini: a UK twin birth cohort with a focus on early childhood weight trajectories, appetite and the family environment. Twin Res Hum Genet 13, 72-78.

10. Office for National Statistics (2005) National Statistics SocioEconomic Classification: User Manual. Newport: Office for National Statistics.

11. Cole TJ, Freeman JV \& Preece MA (1995) Body mass index reference curves for the UK, 1990. Arch Dis Child 73, 25-29.

12. Foster E, Hawkins A \& Adamson A (2010) Young Person's Food Atlas - Pre-School. London: Food Standards Agency. 
13. Fitt E, Mak TN, Stephen AM, et al. (2010) Disaggregating composite food codes in the UK National Diet and Nutrition Survey food composition databank. Eur J Clin Nutr 64, Suppl. 3, S32-S36.

14. Food Standards Agency (2002) McCance and Widdowson's The Composition of Foods, 6th Summary Edition. Cambridge: Royal Society of Chemistry.

15. Scientific Advisory Committee on Nutrition (SACN) (2011) Dietary Reference Values for Energy 2011. London: The Stationery Office.

16. Department of Health (1991) Dietary Reference Values for Food Energy and Nutrients for the United Kingdom, Report on Health and Social Subjects no. 41. London: Committee on Medical Aspects of Food Policy. https://www.gov.uk/ government/uploads/system/uploads/attachment_data/file/ 265266/familyfood-method-rni-12dec13.pdf (accessed April 2015).

17. Scientific Advisory Committee on Nutrition (SACN) (2015) Carbohydrates and health report. Department of Health and Food Standards Agency. https://www.gov.uk/government/ uploads/system/uploads/attachment_data/file/445503/SACN_ Carbohydrates_and_Health.pdf (accessed December 2015).

18. Scientific Advisory Committee on nutrition (SACN) (2003) Salt and Health. London: The Stationery Office.

19. Scientific Committee on Food (2006) Tolerable upper intake levels of vitamins and minerals. European Food Safety Authority. http://www.efsa.europa.eu/en/ndatopics/docs/ ndstolerableuil.pdf (accessed June 2015).

20. Pimpin L, Ambrosini GL, Llewellyn CH, et al. (2013) Dietary intake of young twins: nature or nurture? Am J Clin Nutr 98, 1326-1334.

21. Gibson S \& Sidnell A (2014) Nutrient adequacy and imbalance among young children aged 1-3 years in the UK. Nutr Bull 39, 172-180.

22. Bates B, Lennox A, Prentice A, et al. (2014) National Diet and Nutrition Survey Results from Years 1, 2, 3 and 4 (combined) of the Rolling Programme (2008/2009-2011/2012). London: Public Health England.

23. Eloranta AM, Lindi V, Schwab U, et al. (2012) Dietary factors associated with overweight and body adiposity in Finnish children aged 6-8 years: the PANIC Study. Int J Obes (Lond) 36, 950-955.

24. Escribano J, Luque V, Ferre N, et al. (2012) Effect of protein intake and weight gain velocity on body fat mass at 6 months of age: the EU Childhood Obesity Programme. Int $J$ Obes (Lond) 36, 548-553.

25. Pimpin L, Jebb S, Johnson L, et al. (2016) Dietary protein intake is associated with BMI and weight up to 5 years of age in a prospective cohort of twins. Am J Clin Nutr 103, 389-397.
26. Günther AL, Buyken AE \& Kroke A (2007) Protein intake during the period of complementary feeding and early childhood and the association with body mass index and percentage body fat at $7 \mathrm{y}$ of age. Am J Clin Nutr 85, 1626-1633.

27. Brown IJ, Tzoulaki I, Candeias V, et al. (2009) Salt intakes around the world: implications for public health. Int $J$ Epidemiol 38, 791-813.

28. McLean RM (2014) Measuring population sodium intake: a review of methods. Nutrients $\mathbf{6}, 4651-4662$.

29. Holick MF (2004) Sunlight and vitamin D for bone health and prevention of autoimmune diseases, cancers, and cardiovascular disease. Am J Clin Nutr 80, 1678-1688.

30. Baker RD \& Greer FR (2010) Diagnosis and prevention of iron deficiency and iron-deficiency anemia in infants and young children (0-3 years of age). Pediatrics 126, 1040-1050.

31. Department of Health (2010) Vitamin D: an essential nutrient for all...but who is at risk of vitamin D deficiency? Important information for healthcare professionals. http://webarchive. nationalarchives.gov.uk/+/www.dh.gov.uk/en/publicationsand statistics/publications/publicationspolicyandguidance/dh_ 115370 (accessed May 2015).

32. Scientific Advisory Committee on Nutrition (SACN) (2015) Draft Vitamin D and Health Report. Department of Health and Food Standards Agency. https://www.gov.uk/govern ment/uploads/system/uploads/attachment_data/file/447402/ Draft_SACN_Vitamin_D_and_Health_Report.pdf (accessed December 2015).

33. Livingstone MB, Prentice AM, Strain JJ, et al. (1990) Accuracy of weighed dietary records in studies of diet and health. BMJ 300, 708-712.

34. Stevens EE, Patrick TE \& Pickler R (2009) A history of infant feeding. J Perinat Educ 18, 32-39.

35. Bingham SA, Gill C, Welch A, et al. (1994) Comparison of dietary assessment methods in nutritional epidemiology: weighed records v. $24 \mathrm{~h}$ recalls, food-frequency questionnaires and estimated-diet records. Br J Nutr $\mathbf{7 2}$, 619-643.

36. Burrows TL, Martin RJ \& Collins CE (2010) A systematic review of the validity of dietary assessment methods in children when compared with the method of doubly labeled water. J Am Diet Assoc 110, 1501-1510.

37. Lanigan JA, Wells JC, Lawson MS, et al. (2001) Validation of food diary method for assessment of dietary energy and macronutrient intake in infants and children aged 6-24 months. Eur J Clin Nutr 55, 124-129. 